12

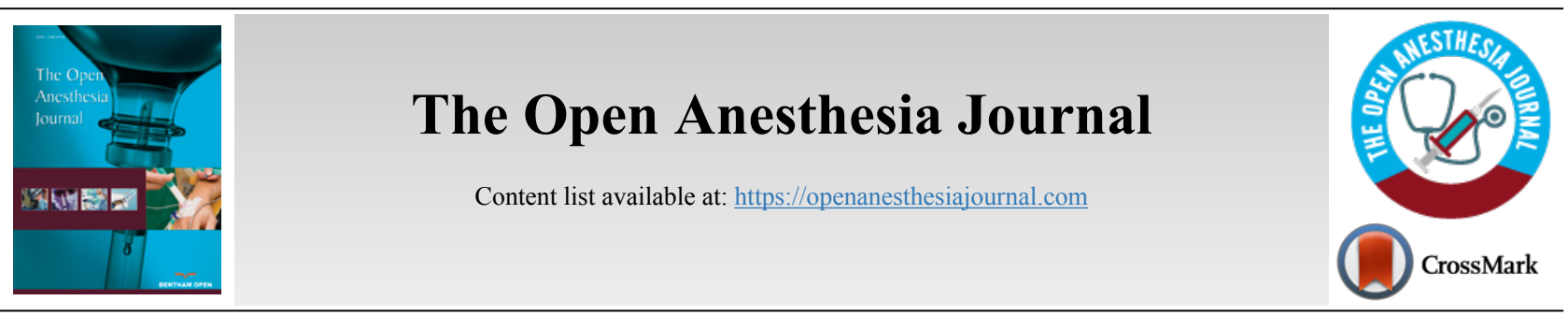

RESEARCH ARTICLE

\title{
The Use of Milrinone Versus Conventional Treatment for the Management of Life-Threatening Bronchial Asthma
}

\author{
Amr Sobhy", Doaa M. K. Eldin and Hany V. Zaki \\ Department of Anesthesia, Ain Shams University, Cairo, Egypt
}

\begin{abstract}
:
Background and Aims:

In our study, we investigated the effectiveness of intravenous milrinone in life-threatening bronchial asthma as compared to conventional treatment.

Methods:

Fifty patients aged 18-50 years, presenting with life-threatening asthma were enrolled in a Randomised Controlled Trial (RCT). They were randomly allocated into Group C (25 patients): who received the standard pharmacotherapy and placebo, and Group M (25 patients): who in addition to the standard therapy, received $25 \mu \mathrm{g}$ milrinone as an initial slow IV bolus diluted in $10 \mathrm{ml}$ of normal saline. The following data were recorded: PEFR (Peak Expiratory Flow Rate) expressed as a percentage of the patient's previous value, Respiratory Rate (RR), MABP (Mean Arterial Blood Pressure), arterial blood gases, and the number of patients requiring mechanical ventilation. Differences between groups were tested using Analysis of Variance (ANOVA) for quantitative variables with post hoc using the Least Significant Difference (LSD) test, and Chi square test for categorical variables.

Results:

Group M showed marked improvement in PEFR that was highly significant $(P<0.001) 10$ min after injection and significant after one hour from the start of treatment in comparison to Group $\mathrm{C}$. There was also an improvement in $\mathrm{RR}$ and $\mathrm{PO}_{2}$ that was significant in group $\mathrm{M}$. Milrinone was associated with a reduction in MABP only after $10 \mathrm{~min}$ from injection, and showed a statistically significant decrease in the number of patients requiring mechanical ventilator support $(P<0.05)$.

Conclusion:

Milronine is a promising agent as a rescue drug in the treatment of life-threatening bronchial asthma.
\end{abstract}

Keywords: Milrinone, Status asthmatics, Phosphodiesterase 3 inhibitors, Bronchial asthma, Randomised controlled trial, Airways.

\begin{tabular}{|l|l|l|r}
\hline Article History & Received: January 16, 2019 & Revised: March 25, 2019 & Accepted: April 02, 2019
\end{tabular}

\section{INTRODUCTION}

Asthma is a chronic disease of the airways, characterized by variable and recurring symptoms, airflow obstruction, bronchial hyper responsiveness and inflammation. In severe exacerbations, intensive care admission may be necessary. Pharmacological treatment includes $\beta_{2}$ agonists, steroids, anti-cholinergic agents, magnesium sulphate, and sometimes aminophylline [1].

While most of the cases of bronchial asthma can be controlled with medication, it is estimated that $5-10 \%$ of asthmatic

\footnotetext{
* Address correspondence to this author at the Department of Anesthesia, Ain Shams University, Cairo, Egypt; Tel: 002010694383 ;

Email: dr.amrsobhy2013@gmail.com
}

patients worldwide are considered to have the most severe persistent form of the disease that does not respond well to standard treatment. These people are likely to have more frequent attacks and are more at risk of a fatal attack [2].

In the past 25 years, literature has suggested the therapeutic potential of phosphodiesterase inhibitors in asthma however none of these drugs have been used clinically for this indication [3].

Milrinone is a bipyridine compound that selectively inhibits phosphodiesterase iso-enzyme 3 (PDE-3). Phosphodiesterases are a family of enzymes that inactivate cAMP and cGMP. Inhibition of PDE results in increased cAMP and intra- 
cellular ionized calcium in the myocyte, resulting in increased myocardial contractility. In smooth muscle cells, PDE inhibitors cause an increase in cAMP and cGMP resulting in relaxation of bronchial smooth muscle cells and bronchodilatation [4].

Milrinone is active orally as well as parenterally but is available only in parenteral form. It has an elimination half life of 3-6 hours with $10-40 \%$ being excreted in the urine [4].

The objective of this study is to assess the effectiveness of using milrinone as a rescue drug in life-threatening bronchial asthma.

\section{METHODS}

In a randomised prospective controlled trial, parallel study was conducted after approval of the Research Ethics Committee (REC), with trial registry number PACTR20180 2002998973. An informed written consent was obtained from every patient or his/her first kin relative. A total of fifty patients were enrolled from November 2017 till April 2018.

Patients included in this study were of both sexes, aged 18-50 years old, presenting with life-threatening asthma according to the criteria of the British Guideline on the management of asthma 2008, revised October 2014 [5]. Life-threatening asthma is defined as any one or more of the following criteria:

[1] PEFR (Peak Expiratory Flow Rate) $<33 \%$ of best or predicted

[2] $\mathrm{SpO}_{2}$ (Oxygen Saturation) $<92 \%$

[3] $\mathrm{PaO}_{2}$ (Arterial Partial Pressure of Oxygen $)<8 \mathrm{kPa}(60$ $\mathrm{mm} \mathrm{Hg}$ )

[4] Normal $\mathrm{PaCO}_{2}$ (Arterial Partial Pressure of Carbon Dioxide) (4.6-6.0 kPa) $(35-45 \mathrm{~mm} \mathrm{Hg})$

[5] Silent chest

[6] Cyanosis

[7] Poor respiratory effort

[8] Arrhythmia

[9] Exhaustion, altered conscious level

[10] Hypotension

Patients excluded from this study were those with preexisting heart failure, hypotensive patients, stenotic or obstructive valvular disease or other outlet obstruction, patients with pre-existing arrhythmia or pneumonia and those who required mechanical ventilation in the first hour of the study.

Immediately following admission, a detailed history was taken regarding physical health, coexisting medical problems, current medications, allergies, if possible and thorough clinical examination (chest auscultation, respiratory muscle paradox, Respiratory Rate RR). Blood pressure, heart rate, ECG. Baseline ABG (Arterial Blood Gas) and Peak Expiratory Flow Rate (PEFR) were monitored of the patients.

All eligible patients received conventional treatment for life-threatening asthma according to the latest British Guideline on the management of asthma 2008, revised October 2014 [5]. Treatment consisted of: Supplementary $\mathrm{O}_{2}$ to all hypoxaemic patients $\left(\mathrm{SpO}_{2}<92 \%\right)$ to maintain $\mathrm{SPO}_{2}$ level 94-98\%, high dose inhaled $\beta_{2}$ agonist or nebulized $\beta_{2}$ agonist (salbutamol), nebulized ipratropium bromide $(0.5 \mathrm{mg}$ every 20 minutes repeated three times, then 4-6 hourly), hydrocortisone $100 \mathrm{mg} /$ 6 hours, and magnesium sulphate 1.2-2 g intravenous (IV) infusion over 20 minutes.

Patients were mechanically ventilated (after failed medical treatment) with non-invasive ventilation (or invasive ventilation in case of its contraindication or failure) according to the following criteria:

[1] Resistant hypoxaemia to $\mathrm{FiO}_{2}>0.6$ with $\mathrm{PaO}_{2}<$ $60 \mathrm{mmHg}$.

[2] Hypercapnia $\mathrm{PaCO}_{2}>50 \mathrm{mmHg}$ or with $\mathrm{pH}<7.2$

[3] Severe tachypnoea with RR $>40$.

[4] Disturbed conscious level.

[5] Haemodynamic disturbance related to respiratory failure (dysrhythmias, hypotension 30\% reduction of basal blood pressure level).

Patients were then randomly assigned by computer generated random sequence into two groups C \& M, 25 patients each:

Group C: Received the standard pharmacotherapy as described above and placebo (10 $\mathrm{ml}$ saline IV).

Group M: in addition to the therapy given to group C, received $25 \mu \mathrm{g}$ milrinone as an initial slow IV bolus diluted in $10 \mathrm{ml}$ of normal saline. Within 10 minutes, if this dose did not provide effective relief it was followed by another slow IV bolus dose of $25 \mu \mathrm{g}$ milrinone.

The following data were collected and recorded: respiratory rate every $10 \mathrm{~min}$ for clinical purposes and recorded after 1 hour, PEFR expressed as a percentage of the patient's best predicted value, measured by peak flowmeter assessed at 10 min and after 1 hour, MABP (Mean Arterial Blood Pressure) assessed at $10 \mathrm{~min}$ and after 1 hour, $\mathrm{SPO}_{2}$ continuously applied and recorded after 1 hour. $\mathrm{PaO}_{2}$ and $\mathrm{PaCO}_{2}$ were measured and recorded after 1 hour, as well as the number of patients requiring mechanical ventilation after failed medical therapy.

The primary endpoint of the study is to assess the relief of status asthmaticus by milrinone in the form of improvement in PEFR, and the secondary endpoint is to evaluate the effectiveness of milrinone in reducing the number of patients requiring mechanical ventilation.

The points at which the study was terminated include severe hypotension, malignant arrhythmias, and mechanical ventilation within the first hour.

Sample size calculation was done using PS (version 3.0.43, Department of Biostatistics, Vanderbilt University, located in Nashville, United States), based upon the assumption that using milrinone may improve PEFR as a percentage of predicted value by $20 \%$ and taking power 0.81 and alpha error 0.05 . A minimum sample size of 25 patients was calculated for each group. Eligible patients were randomly assigned following 
Table 1. Baseline and demographic data recorded.

\begin{tabular}{|c|c|c|c|c|c|c|c|c|}
\hline \multirow[t]{2}{*}{ Parameters } & \multicolumn{3}{|c|}{$\begin{array}{c}\text { Group C } \\
(n=25)\end{array}$} & \multicolumn{3}{|c|}{$\begin{array}{c}\text { Group M } \\
(n=25)\end{array}$} & \multicolumn{2}{|c|}{ Tests } \\
\hline & Mean & \pm & SD & Mean & \pm & SD & $t / \mathbf{X}^{2}$ & P-value \\
\hline Age (years) & 40.85 & \pm & 6.54 & 41.12 & \pm & 5.37 & 0.160 & 0.874 \\
\hline $\operatorname{Sex}(M / F)$ & \multicolumn{3}{|c|}{$14 / 11$} & \multicolumn{3}{|c|}{$12 / 13$} & 0.321 & 0.571 \\
\hline Basal (PEFR) \% & 32.49 & \pm & 3.51 & 31.08 & \pm & 4.29 & 1.272 & 0.209 \\
\hline RR (cycles/min) & 41.38 & \pm & 4.75 & 42.69 & \pm & 4.38 & 1.014 & 0.315 \\
\hline $\mathrm{PaO}_{2} \mathrm{mmHg}$ (Room Air) & 56.87 & \pm & 7.23 & 57.22 & \pm & 6.46 & 0.180 & 0.857 \\
\hline $\mathrm{SPO}_{2}$ (Room Air) & 86.74 & \pm & 8.65 & 87.61 & \pm & 7.41 & 0.382 & 0.704 \\
\hline $\mathrm{pH}$ & 7.21 & \pm & 0.09 & 7.22 & \pm & 0.08 & 0.174 & 0.821 \\
\hline $\mathrm{PaCO}_{2}(\mathrm{mmHg})$ & 52.45 & \pm & 3.66 & 53.16 & \pm & 4.16 & 0.641 & 0.524 \\
\hline MABP $(\mathrm{mmHg})$ & 98.07 & \pm & 4.53 & 96.74 & \pm & 5.98 & 0.886 & 0.379 \\
\hline
\end{tabular}

Data are presented as mean \pm standard deviation. Group C: standard pharmacotherapy and placebo, Group M: standard pharmacotherapy and $25 \mu \mathrm{g}$ milrinone slow IV bolus, PEFR: peak expiratory flow rate, RR: respiratory rate, $\mathbf{P a O}_{2}$ : arterial partial pressure of oxygen, $\mathbf{S p O}_{2}$ : arterial oxygen saturation, $\mathbf{p H}$ : potential of hydrogen, $\mathrm{PaCO}_{2}$ arterial partial pressure of carbon dioxide, MABP: mean arterial blood pressure.

Table 2. PEFR measured 10 minutes and 1 hour after the start of treatment.

\begin{tabular}{|c|c|c|c|c|c|c|c|c|c|c|}
\hline \multirow[t]{2}{*}{ (PEFR)\% mmHg } & \multicolumn{4}{|c|}{$\begin{array}{c}\text { Group C } \\
(\mathrm{n}=\mathbf{2 5})\end{array}$} & \multicolumn{4}{|c|}{$\begin{array}{c}\text { Group M } \\
(\mathbf{n}=\mathbf{2 5})\end{array}$} & \multicolumn{2}{|c|}{ T-test } \\
\hline & Mean & \pm & SD & \multirow{2}{*}{ \%of change } & Mean & \pm & SD & \multirow{2}{*}{$\%$ of change } & $\mathbf{t}$ & $P$-value \\
\hline Baseline & 32.49 & \pm & 3.51 & & 31.08 & \pm & 4.29 & & 1.272 & 0.209 \\
\hline 10 min after injection & 51.74 & \pm & 5.26 & 59.2 & 64.89 & \pm & 6.87 & 108.8 & 7.599 & $<0.001^{* *}$ \\
\hline $1 \mathrm{~h}$ after injection & 70.75 & \pm & 7.18 & 117.8 & 77.65 & \pm & 7.29 & 149.8 & 3.372 & $0.002 *$ \\
\hline
\end{tabular}

Data are presented as mean \pm standard deviation. Percentage of change is compared to the baseline value, calculated as: $(51.74-32.49) \div 32.49$. Group C: standard pharmacotherapy and placebo, Group M: standard pharmacotherapy and $25 \mu \mathrm{g}$ milrinone slow IV bolus, PEFR: peak expiratory flow rate. **Statistically highly significant. *Statistically significant.

Table 3. Parameters measured after 1 hour from the start of treatment.

\begin{tabular}{|c|c|c|c|c|c|c|c|c|}
\hline \multirow{2}{*}{ After one hour } & \multicolumn{3}{|c|}{$\begin{array}{c}\text { Group C } \\
(\mathbf{n}=\mathbf{2 5})\end{array}$} & \multicolumn{3}{c|}{$\begin{array}{c}\text { Group M } \\
(\mathbf{n}=\mathbf{2 5})\end{array}$} & \multicolumn{3}{c|}{ Tests } \\
\cline { 2 - 10 } & Mean & \pm & SD & Mean & \pm & SD & t/ $^{2}$ & P-value \\
\hline $\mathrm{RR}($ cycles/min) & 25.84 & \pm & 3.15 & 21.35 & \pm & 3.5 & 4.768 & $<0.001^{* *}$ \\
\hline $\mathrm{PaO}_{2}(\mathrm{mmHg})$ & 72.67 & \pm & 4.38 & 81.24 & \pm & 5.09 & 6.381 & $<0.001^{* *}$ \\
\hline $\mathrm{SpO}_{2}$ & 93.24 & \pm & 6.72 & 93.56 & \pm & 7.54 & 0.158 & 0.874 \\
\hline $\mathrm{pH}$ & 7.25 & \pm & 0.07 & 7.29 & \pm & 0.09 & 1.754 & 0.085 \\
\hline $\mathrm{PaCO}_{2}(\mathrm{mmHg})$ & 43.84 & \pm & 4.8 & 44.35 & \pm & 5.1 & 0.364 & 0.717 \\
\hline $\mathrm{No}^{2}$ requiring MV & \multicolumn{3}{|c|}{$9 / 16(36 \%)$} & \multicolumn{3}{|c|}{$3 / 22(12 \%)$} & 3.947 & $0.047^{*}$ \\
\hline
\end{tabular}

Data are presented as mean \pm standard deviation. Number of patients requiring mechanical ventilation expressed as percentage. Group C: standard pharmacotherapy and placebo, Group M: standard pharmacotherapy and $25 \mu \mathrm{g}$ milrinone slow IV bolus, $\mathbf{M V}$ : mechanical ventilation, $\mathbf{R R}$ : respiratory rate, PaO $\mathbf{O}_{2}$ : arterial partial pressure of oxygen, $\mathrm{SpO}_{2}$ : arterial oxygen saturation, $\mathbf{p H}$ : potential of hydrogen, $\mathbf{P a C O}_{2}$ arterial partial pressure of carbon dioxide. ${ }^{*}$ Statistically highly significant $*$ Statistically significant

simple randomization procedures by an independent researcher, using computer generated random sequence into two treatment groups. The allocation sequence was concealed from the researchers enrolling and assessing patients in sequentially numbered, opaque, sealed and stapled envelopes containing cards with the treatment code. Aluminum foil was put inside to render the envelope impermeable to intense light. After assessing eligibility, the patient was enrolled and then the intervention was allocated. The name and date of birth of the patient were written on the envelope. Carbon paper inside the envelope transferred this information onto the allocation card inside, and then the envelope was opened

\subsection{The Clinical Trial Registry is the Pan African Clinical Trial Registry PACTR201802002998973}

Preparation of the different medications was performed by an independent nurse according to the treatment codes. The patients, the enrolling and assessing physicians, and data analysts were kept blind to the allocation arms of the study.

Data were entered into a computer and checked for completeness and consistency. Treatment groups were analysed as coded. Quantitative variables were described as means and standard deviations. Categorical variables were described as numbers and percentages. Differences between groups were tested using Analysis of Variance (ANOVA) for quantitative 
variables with post hoc using the Least Significant Difference (LSD) test, and Chi square test for categorical variables. All analyses were performed on an intention-to-treat basis with two-sided level of significance at $P$-value $\leq 0.05$ using IBMSPSS program version 21 .

\section{RESULTS}

A total of fifty patients were enrolled in this trial, 25 patients in each of the treatment groups. Age and gender were homogeneously distributed in both groups. As regards, baseline values of the parameters measured (PEFR, $\mathrm{RR}, \mathrm{PaO}_{2}, \mathrm{SPO}_{2}$, $\mathrm{pH}, \mathrm{PaCO}_{2}$ and MABP) there was no statistically significant difference between both groups $(P>0.05)$ (Table 1). None of the patients in our study experienced severe hypotension, malignant arrhythmias or required mechanical ventilation during the first hour.

PEFR measured 10 minutes after injection improved from $31.08 \%$ to $64.89 \%$ in group $\mathrm{M}$, and improved from $32.49 \%$ to $51.74 \%$ in the control group. The difference between both measurements at 10 minutes was highly significant $(P<$ $0.001)$. PEFR measurements at one hour were $77.65 \%$ in group $\mathrm{M}$, compared to $70.75 \%$ in group $\mathrm{C}(P=0.002)$ (Table 2$)$.

Measurements of RR and $\mathrm{PaO}_{2}$ one hour after injection revealed highly significant improvement in group $\mathrm{M}$ as compared to group $\mathrm{C}(P<0.001) . \mathrm{SpO}_{2}$ improved in both groups as compared to baseline readings, but the difference between both groups was not statistically significant $(P=$ 0.884). $\mathrm{PaCO}_{2}$ and $\mathrm{pH}$ did not show any statistical difference between both groups after one hour $(P$ values $0.085,0.717$ respectively) (Table 3 ).

Regarding the number of patients requiring mechanical ventilation nine out of 25 patients in group $\mathrm{C}$ needed mechanical ventilation (36\%) compared to three out of 25 patients in group $\mathrm{M}(12 \%)$. This difference was statistically significant $(P=0.047)$ (Table 3).

Serial blood pressure readings showed a drop in mean arterial blood pressure 10 minutes after the start of treatment in the milrinone group $(74.98 \pm 4.12 \mathrm{mmHg})$ as compared to group C $(97.53 \% \pm 5.26 \mathrm{mmHg})$ which was statistically highly significant $(P<0.001)$. However one hour after the start of treatment there was no significant difference between MABP readings in both groups $(P<0.654)$ (Table 4).

\section{DISCUSSION}

The treatment of status asthmaticus in refractory bronchial asthma presents a challenge to the physician and health services. In our study, we investigated the effectiveness of intravenous milrinone as a rescue drug in life-threatening bronchial asthma as compared to conventional treatment.

Our results showed that milrinone caused a significant improvement in PEFR both at 10 minutes after injection (64.89\%), and almost reaching normal values $(77.65 \%)$ one hour after injection. This was associated with a significant improvement in respiratory rate and $\mathrm{PaO}_{2}$. Other variables such as $\mathrm{SpO}_{2}, \mathrm{PaCO}_{2}$ and $\mathrm{pH}$ showed clinical improvement compared to baseline readings but did not show significant difference between the milrinone and the control group in com- parison. The relationship between $\mathrm{PaO}_{2}$ and $\mathrm{SpO}_{2}$ in the oxyhaemoglobin dissociation curve is $\mathrm{S}$-shaped rather than linear. Consequently, wide changes in $\mathrm{PaO}_{2}$ are met by minor changes in $\mathrm{SpO}_{2}$ causing the difference between both groups to be statistically non-significant.

Milrinone group showed a significant reduction in the overall number of patients requiring mechanical ventilation. Regarding the haemodynamic effects, the milrinone group showed a transient drop in Mean Arterial Blood Pressure (MABP) 10 minutes after the injection that did not persist even one hour after the injection. This drop in MABP was statistically significant as compared to the control group, yet clinically it was not significant as it did not drop below 70 $\mathrm{mmHg}$. None of the patients in our study developed malignant arrhythmias.

Since the early 1990s, the sparse research into PDE 3 inhibitors for pulmonary uses did not lead to the use of any of these drugs in the treatment of bronchial asthma. However several previous studies have studied the effect of various members of PDE 3 family on bronchial asthma and acute exacerbations of COPD.

The results of our study correlate with those of Beute, 2014 [1] who examined the effect of another member of the PDE 3 inhibitors, enoximone, for the emergency treatment of status asthmaticus. Eight patients with status asthmaticus, six of whom were maximally treated, were consequently treated with enoximone in their refractory phase. A rapid bolus of $100 \mathrm{mg}$ enoximone was administered intravenously followed by an infusion of $8 \mathrm{mg} / \mathrm{hr}$. It was found that treatment with enoximone worked instantaneously. Resolution of asthma symptoms was immediate. The onset of action was within seconds of the start of injection, suggesting an effect at first passage through the lungs, resolving bronchospasm. Bronchodilation was imme-diate without any cardiovascular side effects. It also enabled shorter hospital and ICU stays, and reduced the risk for mechanical ventilation.

One of the earliest studies was performed on selective PDE 3 inhibitors by Leeman and colleagues in 1987. A group of 19 patients admitted to intensive care with decompensated COPD was treated with enoximone $3 \mathrm{mg} / \mathrm{kg}$ over 15 minutes. Heart rate, mean systemic arterial pressure, arterial blood gases, respiratory rate, minute ventilation, lung resistance and lung compliance were recorded as baseline measurements at 30 and 60 minutes after the end enoximone infusion. They recorded an increase in heart rate in mechanically ventilated patients only. Lung resistance decreased and dynamic lung compliance increased after enoximone infusion in spontaneously breathing patients. Side effects recorded in one patient which were significant, such assystemic hypotension, poorly tolerated tachycardia, atrial fibrillation bradycardia, dyspnoea, facial flush and headache. Side effects were attributed to excessive systemic vasodilation. They concluded that enoximone was effective in reducing bronchomotor tone, and that the high frequency of side effects was probably due to the high excessive intravenous dose of enoximone [6].

Our results also agree with those of Fujimura and colleagues 1995, who studied the effect of cilostazol, another 
Table 4. MABP values measured 10 minutes and 1 hour after the start of treatment.

\begin{tabular}{|c|c|c|c|c|c|c|c|c|}
\hline \multirow[t]{2}{*}{ MABP (mmHg) } & \multicolumn{3}{|c|}{$\begin{array}{c}\text { Group C } \\
(n=25)\end{array}$} & \multicolumn{3}{|c|}{$\begin{array}{c}\text { Group M } \\
(\mathrm{n}=\mathbf{2 5})\end{array}$} & \multicolumn{2}{|c|}{ Tests } \\
\hline & Mean & \pm & SD & Mean & \pm & SD & $t / X^{2}$ & $P$-value \\
\hline Baseline & 98.07 & \pm & 4.53 & 96.74 & \pm & 5.98 & 0.886 & 0.380 \\
\hline $\mathbf{1 0} \mathbf{~ m i n}$ after injection & 97.53 & \pm & 5.26 & 74.98 & \pm & 4.12 & 16.875 & $<0.001 * *$ \\
\hline $\mathbf{1} \mathbf{h}$ after injection & 94.28 & \pm & 5.39 & 93.67 & \pm & 4.07 & 0.452 & 0.654 \\
\hline
\end{tabular}

Data are presented as mean \pm standard deviation. Group C: standard pharmacotherapy and placebo, Group M: standard pharmacotherapy and $25 \mu \mathrm{g}$ milrinone slow IV bolus, MABP: mean arterial blood pressure. ${ }^{* * S}$ Statistically highly significant.

selective PDE3 inhibitor, on bronchial responsiveness in normal subjects. A group of eight healthy subjects received 200 $\mathrm{mg}$ of oral cilostazol or placebo in random order. The subjects underwent metacholine challenge test. The concentration of metacholine causing a $20 \%$ fall in FEV1 and the mean value of maximum expiratory flow on the flow-volume curve were recorded. They demonstrated that cilostazol reduced bronchial responsiveness in healthy volunteers and asthmatics. However, all subjects complained of headache ranging from mild to severe when cilostazol was given which may be attributed to cerebral vasodilator effect [7].

A further study by Fujimura and coworkers in 1997, examined the effect of a single oral dose of cilostazol on bronchial hyper-responsiveness in elderly asthmatic patients with clinically stable asthma. Each subject received $100 \mathrm{mg}$ of cilostazol, $200 \mathrm{mg}$ of theophylline as a positive control or placebo in a random order. The subjects then underwent a metacholine challenge test of 3 hours after each drug administration. The mean value of provocative concentration of metacholine causing a $20 \%$ fall in $\mathrm{FEV}_{1}$ was recorded. Their study suggested that cilostazol has bronchodilator and bronchoprotective effects in elderly asthmatic patients [3].

The effect of aerosolized PDE 3 inhibitor olprinone was studied by Fujimura and colleagues in 1999. They performed a double-blinded randomized trial in which aerosolized olprinone was compared to salbutamol and vehicle in nine asthmatic patients on three occasions one week apart. Olprinone at a dose of $2 \mathrm{mg}$, salbutamol at a dose of $2.5 \mathrm{mg}$ (dissolved in Dsorbitol solution), or vehicle was inhaled from a nebulizer. Spirometry was assessed over $60 \mathrm{~min}$. Significant increases in FEV1 were observed until 45 min after inhalation of olprinone without adverse cardiovascular effects. Mean maximal increases in FEV1 were $16.0 \pm 4.0$ and $20.5 \pm 4.2 \%$ with olprinone and salbutamol, respectively $(P=0.28)$. They concluded that the bronchodilator effect of olprinone was greater than that of salbutamol in four of the nine patients. Their results suggested that inhaled olprinone may be useful as airway smooth muscle relaxant in the treatment of asthma [8].

Previous animal studies on milrinone have shown that it was as effective as an inhibitor of antigen-induced bronchoconstriction in isolated rat lungs [9]. Further studies showed that intra-tracheal administration of milrinone effectively reduced bronchoconstriction in cats in a dose-dependent fashion without substantial systemic side effects. There were no treatment-associated changes in mean arterial pressure or heart rate [10]. Another contradictory study showed that intravenous injection of milrinone showed weak, or no, inhibitory effects against bronchoconstriction produced by aerosolized antigen or histamine in anesthetized ventilated guinea pigs [11]. Inhaled zardaverine, a dual inhibitor of PDE3 and PDE4, also exhibited a bronchodilator effect in asthmatic animals [12].

Although it is expected that PDE inhibitors may produce a profound drop in arterial blood pressure due to their vasodilator effects, in our study, milrinone did not result in profound haemodynamic instability. A reason might be that in heart failure milrinone is given in much higher doses as compared to our study. An initial loading dose of $50 \mathrm{mcg} / \mathrm{kg}$ over 10 minutes followed by $0.375-0.75 \mathrm{mcg} / \mathrm{kg} / \mathrm{min}$ is the dose described for the treatment of severe congestive heart failure [13]. The dose used in our study was considerably lower and the duration of administration was substantially shorter.

Limitations of our study were that we did not assess the effectiveness of continuous infusion of milrinone, and whether or not continuous infusion may possibly reduce the duration of mechanical ventilation and ICU stay.

\section{CONCLUSION AND RECOMMENDATIONS}

We conclude that milrinone is a promising agent as a rescue drug in the treatment of life-threatening bronchial asthma with minimal hemodynamic side effects.

\section{ETHICS APPROVAL AND CONSENT TO PARTICI- PATE}

The study was conducted after approval of the Research Ethics Committee (REC), with trial registry number PACTR20180 2002998973.

\section{HUMAN AND ANIMAL RIGHTS}

No Animals were used in this research. All human research procedures followed were in accordance with the ethical standards of the committee responsible for human experimentation (institutional and national), and with the Helsinki Declaration of 1975, as revised in 2013.

\section{CONSENT FOR PUBLICATION}

An informed written consent was obtained from every patient or his/her first kin relative.

\section{AVAILABILITY OF DATA AND MATERIALS}

Not applicable.

\section{FUNDING}

None. 


\section{CONFLICT OF INTEREST}

The authors declare no conflict of interest, financial or otherwise.

\section{ACKNOWLEDGEMENTS}

Declared none.

\section{REFERENCES}

[1] Beute J. Emergency treatment of status asthmaticus with enoximone. Br J Anaesth 2014; 112(6): 1105-8. [http://dx.doi.org/10.1093/bja/aeu048] [PMID: 24638233]

[2] Asthma and Allergy Foundation of America. Available from http://www.aafa.org2018.

[3] Fujimura M, Kamio Y, Myou S, Hashimoto T, Matsuda T. Effect of a phosphodiesterase 3 inhibitor, cilostazol, on bronchial hyperresponsiveness in elderly patients with asthma. Int Arch Allergy Immunol 1997; 114(4): 379-84.

[http://dx.doi.org/10.1159/000237698] [PMID: 9414143]

[4] Katzung BG, Parmley WW. Drugs used in Heart Failure.Basic and Clinical Pharmacology. 10th ed. McGraw Hill 2007; pp. 198-210.

[5] British Guideline on the Managament of Asthma. May 2008 revised 2014. Available from http://www.sign.ac.uk/pdf/sign101.pdf

[6] Leeman M, Lejeune P, Melot C, Naeije R. Reduction in pulmonary hypertension and in airway resistances by enoximone (MDL 17,043) in decompensated COPD. Chest 1987; 91(5): 662-6.

[http://dx.doi.org/10.1378/chest.91.5.662] [PMID: 2952467]
[7] Fujimura M, Kamio $Y$, Saito M, Hashimoto T, Matsuda T. Bronchodilator and bronchoprotective effects of cilostazol in humans in vivo. Am J Respir Crit Care Med 1995; 151(1): 222-5. [http://dx.doi.org/10.1164/ajrccm.151.1.7812559] [PMID: 7812559]

[8] Myou S, Fujimura M, Kamio Y, et al. Bronchodilator effect of inhaled olprinone, a phosphodiesterase 3 inhibitor, in asthmatic patients. Am J Respir Crit Care Med 1999; 160(3): 817-20.

[http://dx.doi.org/10.1164/ajrccm.160.3.9812065] [PMID: 10471602]

[9] Post MJ, te Biesebeek JD, Wemer J, van Rooij HH, Porsius AJ. Effects of milrinone, sulmazole and theophylline on adenosine enhancement of antigen-induced bronchoconstriction and mediator release in rat isolated lungs. Pulm Pharmacol 1991; 4(4): 239-46. [http://dx.doi.org/10.1016/0952-0600(91)90017-W] [PMID: 1725275]

[10] Hu H, Takata M, Kusakawa I, Fujita M, Miyasaka K. Intratracheal administration of phosphodiesterase III inhibitor attenuates bronchoconstriction in cats: A preliminary report. Pediatr Pulmonol 1995; 19(6): 360-4.

[http://dx.doi.org/10.1002/ppul.1950190609] [PMID: 7567216]

[11] Ortiz JL, Vallés JM, Martí-Cabrera M, Cortijo J, Morcillo EJ. Effects of selective phosphodiesterase inhibitors on platelet-activating factorand antigen-induced airway hyperreactivity, eosinophil accumulation, and microvascular leakage in guinea pigs. Naunyn Schmiedebergs Arch Pharmacol 1996; 353(2): 200-6.

[http://dx.doi.org/10.1007/BF00168758] [PMID: 8717161]

[12] Brunnée T, Engelstätter R, Steinijans VW, Kunkel G. Bronchodilatory effect of inhaled zardaverine, a phosphodiesterase III and IV inhibitor, in patients with asthma. Eur Respir J 1992; 5(8): 982-5. [PMID: 1426207]

[13] Milrinone Dosage forms and strengths https://reference.medscape. com/drug/milrinone-342433

\section{(c) 2019 Sobhy et al.}

This is an open access article distributed under the terms of the Creative Commons Attribution 4.0 International Public License (CC-BY 4.0), a copy of which is available at: https://creativecommons.org/licenses/by/4.0/legalcode. This license permits unrestricted use, distribution, and reproduction in any medium, provided the original author and source are credited. 